\title{
Using Rapid Bio-assessment and Habitat Evaluation Methods to Understand the Effects of Different Land Uses on a Privately- owned River in Southwest Virginia
}

\author{
Jessica Fitzpatrick ${ }^{1 *}$ and Verl Emrick ${ }^{1}$
}

Private lands comprise the majority of the land area in the United States and serve as reservoirs for biodiversity conservation. Rivers in watersheds containing privately owned agricultural land often experience agricultural disturbances resulting in increased erosion and siltation. It was hypothesized that stream reaches subjected to agricultural disturbance, primarily from livestock, would exhibit decreased habitat quality and increasingly stressed aquatic communities. This study was conducted in the North Fork of the Roanoke River in Montgomery County, Virginia, USA. The Qualitative Habitat Evaluation Index and Use Assessment (QHEI) was applied to measure habitat quality and the Virginia Stream Condition Index (VSCI) to assess ecological health. QHEI and VSCI scores were determined between parcels based on different land uses. The downstream mean QHEI score was 49.7 \pm 3.7 , compared to the upstream score $57.2 \pm$ 6.5. Conversely, the downstream VSCI score was $74.9 \pm 5.4$, compared to the upstream score $60.8 \pm 20.9$. These score discrepancies are likely due to concentrated livestock river access, an upstream low water crossing, degraded banks and increased siltation at the study site which reduced macroinvertebrate abundance, especially pollution-sensitive groups. Management to reduce livestock entry and remove low-water crossing structures may reduce sedimentation and increase VSCI recovery potential. Increasing understanding of factors adversely affecting the ecosystems within private lands, as demonstrated by this research project, improves management efficacy and enhances the area's role in promoting biodiversity conservation. Future research to understand how ecological communities and habitat quality respond to different private land uses should be conducted in southwest Virginia to further advance private land conservation.

\section{INTRODUCTION}

Approximately $60 \%$ of land in the United States is privately owned (Platt, 2004). Private land supports roughly half of all threatened and endangered species within the United States; however, efforts aimed at conserving ecosystems and biodiversity typically focus on public lands (Knight, 1999; Platt, 2004; Jenkins et al., 2015). Consequently, private lands are critical reservoirs of biodiversity and can play a significant role in species conservation efforts (Knight, 1999). In 2015, 56 million acres of private land in the United States were conserved through land trusts, which is twice as much land as is currently managed by the National Park System (Lynsen, 2016). Land trusts are nonprofit organizations that facilitate the preservation of environmental resources, such as wildlife habitat, on private lands by directly owning the land or holding conservation easements (Parker, 2004). Therefore, understanding ${ }^{1}$ Virginia Polytechnic Institute and State University, Blacksburg, VA 24061

*To whom correspondence should be addressed: jess4596@vt.edu

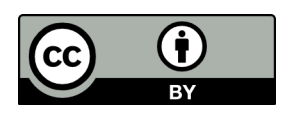

Except where otherwise noted, this work is licensed under https://creativecommons.org/licenses/by/4.0

doi:10.22186/jyi.37.6.47-54 land uses that adversely affect conservation on private land can lead to improved management that promotes ecosystem and conservation services.

The study site is situated in the Southern Appalachians, located in southeastern North America, spanning from West Virginia to northern Alabama. The Southern Appalachians, cover roughly 37.4 million acres, with over $80 \%$ owned privately (Southern Appalachian Vitality Index, 2016a). Approximately $22 \%$ of riparian habitat is disturbed or degraded with $75 \%$ of disturbances related to agricultural land use (Southern Appalachian Vitality Index, 2016b). The Southern Appalachians are a biodiversity hotspot for aquatic species because many streams and rivers drain southwards, which allowed aquatic species to persist during successive glaciations. For example, approximately 345 fish species inhabit Southern Appalachian streams and rivers, which represent more species than occur in all of Europe (Stein et al., 2000; Sutherland et al., 2002). Many of the species, including threatened and endangered species, require high water quality and clean substrate making them sensitive to sediment pollution from agriculture, forestry, urban development, and road construction (Waters, 1995; Sutherland et al., 2002). The specific study site within the Southern Appalachians is the North Fork of the Roanoke River, which transects a largely agricultural watershed. Because the Roanoke Logperch, a federally endangered species, has been confirmed to inhabit the 
North Fork, maintaining good water quality and habitat is a priority making it an ideal waterbody to examine how agricultural land use can affect stream health (Rosenberger, 2007).

In watersheds where agriculture is a prominent land use, elevated nutrient concentrations from runoff (e.g. Nitrogen and Phosphorus) contribute to reduced water quality and aquatic ecosystem health, when compared with watersheds with little or no agricultural use (Omernik, 1976; Corvallis Environmental Research Laboratory, 1977; Wang et al., 1997). Sedimentation and nutrient runoff from agriculture can shift aquatic communities from a diverse assemblage that includes pollution-sensitive species to a homogenized assemblage of pollution-tolerant, generalist species (Blann et al., 2009). Physical disruption associated with agriculture such as river channelization, removal of riparian (bank) vegetation, and livestock use, deteriorates river structure and function to a greater degree than agricultural runoff alone demonstrating the need for an evaluation that analyzes both macroinvertebrate community structure and physical habitat features (Petersen, 1992).

The study site, the North Fork of the Roanoke River, in Montgomery county Virginia, is subjected to two major physical disruptions: livestock access and a low water crossing for vehicles. A low water crossing is a section of road that runs through the waterway and acts as a bridge during low flow conditions but allows water to pass over during higher flow rates. Direct livestock use of waterways negatively affects water quality and quantity, channel morphology, hydrology, riparian soils, instream and riparian vegetation, macroinvertebrate richness metrics, and wildlife (Kauffman and Krueger, 1984; Trimble and Mendel, 1995; Belsky et al., 1999; Herbst et al., 2012). The culverts in low water vehicle crossings, which are tunnels that allow water to flow underneath, often become clogged with organic matter, interrupting water flow, disrupting normal dispersal patterns of aquatic organisms, thus reducing feeding, reproductive activity, and water quality downstream (Clarkin et al., 2006).

Macroinvertebrates (small invertebrates that live on stones, woody debris, sediment, and aquatic vegetation at the bottom of rivers and lakes) are widely used to provide an integrated assessment of site-specific impacts and short-term habitat changes due to their limited migration and relatively short life cycle of around a year (Barbour et al., 1999). Petersen (1992) linked macroinvertebrate community functional structure and taxa richness to the structure of the riparian plant community. Petersen's research demonstrates the importance of physical habitat features such as riparian plant community structure to the greater aquatic ecosystem. Although habitat features and macroinvertebrate communities relate to each other, evaluating both allows for a comprehensive analysis of overall river health.

The health of riverine aquatic systems is measured using various metrics. In the past, metrics of water quality, such as measurements of toxic chemicals, biochemical oxygen demand, or nutrient levels, were collected to determine ecological health (Yoder, 1991). It is now understood that simple chemical monitoring does not provide an integrative ecological condition of aquatic com- munities; instead physical habitat characteristics combined with biological measures may provide a more reliable picture of how well a habitat is supporting biodiversity. Many assessments exist for gauging the condition of an aquatic system including the Benthic Index of Biotic Integrity (B-IBI), River Habitat Survey (RHS), Environmental Protection Agency Rapid Bio-assessment Protocol (EPA RBP), etc. (Raven et al., 1998; Barbour et al., 1999; Llanso and Dauer, 2002). These assessments measure a combination of factors such as macroinvertebrate taxa richness, altitude, slope, watershed features, riparian characterization, instream features, water quality, sediment characterization, etc. Data on macroinvertebrate composition acts as a proxy to monitor stress of aquatic communities and reflects the integrative health of river systems. Abiotic and biotic factors other than macroinvertebrate composition indicate the quality of habitat present and are generally correlated to the habitat features that most significantly impact aquatic communities. Biological assessments use a combination of these factors to give a comprehensive overview and evaluation of the river ecosystem health.

The EPA RBP of streams and wadable rivers utilizes faunal surveys, systematic sampling techniques, and reference conditions to evaluate the health of a waterbody and to establish baseline metrics to monitor recovery and restoration (Barbour et al., 1999). Macroinvertebrate data is collected using RBP to provide an inclusive assessment of river condition that are compared to empirically defined reference conditions (Barbour et al., 1999). In this study, the Virginia Stream Condition Index (VSCI) serves as the reference condition metric as it is specific to Virginian streams. The VSCI was developed specifically using monitoring data collected from Virginian streams to detect biological impairment. The VSCI utilizes benthic macroinvertebrate community composition to evaluate the ecological health of streams and rivers by determining whether aquatic communities are experiencing severe, moderate, fair, good, or excellent conditions (Virginia Department of Environmental Quality, 2008). After sorting, identifying and counting macroinvertebrates following the VSCI methods, a score is derived that is compared to VSCI reference conditions. The MIV metrics used in VSCI provide specific measures of diversity, composition, pollution tolerance, and overall community response to environmental stressors (Virginia Department of Environmental Quality, 2008). VSCI is especially useful in providing an idealized condition of non-coastal riverine systems for comparison as no paired studies exist covering the desired watershed in Virginia.

The Ohio EPA Qualitative Habitat Evaluation Index and Use Assessment (QHEI) is used to give a precise assessment of desired habitat characteristics (Ohio EPA, 2006). QHEI is an index of macro-habitat quality to evaluate the quality of habitat characteristics that generally affect aquatic communities (Rankin, 1989). The QHEI was developed for ease of application using a quantitative scoring system that requires few additional measuring resources while maximizing its explanatory power of how a variety of habitat variables are affecting aquatic vertebrates and invertebrates (Rankin, 1989). 
Sponseller et al. (2001) conducted a study in the Upper Roanoke River in southwestern Virginia to understand how land-use affects macroinvertebrate communities in southern Appalachian headwaters. They found that the relationship between land-cover and macroinvertebrate communities was strongest when measured at the $200 \mathrm{~m}$ sub-corridor scale. This finding suggests that local development near streams markedly alters macroinvertebrate community structure and supports the use of macroinvertebrates to quantify land-use effects on the greater aquatic ecosystem. By comparing land-use effects, the habitat quality and ecological health can be quantitatively compared to determine how they differ between sites in response to various environmental stressors and therefore assess the implications of such stressors for conservation management.

This research contributes to biodiversity conservation on private lands in southwest Virginia. It was hypothesized that stream sections subjected to year-round livestock use and reduced flow rates related to low-water crossing structures, would exhibit increased bank erosion and siltation resulting in lower habitat quality and increasingly stressed aquatic communities. To test this hypothesis, macroinvertebrates were collected from the stream following collection methods detailed by the Rapid Bioassessment Protocol, scored the macroinvertebrates following VSCI techniques and compared those scores to the idealized VSCI reference condition, and evaluated habitat quality using the categories and scoring system of the Qualitative Habitat Evaluation Index. These methods were used to answer the following research questions: How does land use contribute to the degradation of both habitat quality and aquatic community health? What is the current habitat quality and ecological health status of the river ecosystem? What management actions may be applied by landowners to improve the riverine habitat and reduce the stress experienced by the aquatic communities?

\section{METHODS}

\section{Field Methods}

\section{Study Site}

The North Fork of the Roanoke River, from its confluence with the South Fork, drains over $300 \mathrm{~km}^{2}$ and is $74 \%$ forested, $20 \%$ agriculture, and $6 \%$ urban (EPA, 2015). The middle section of the watershed, where the study site is located, is privately owned land with agriculture as a predominant land use. Lands experiencing agricultural disturbances are vulnerable to sedimentation and nutrient pollution caused by runoff from agricultural row crops, pasture, hay production, and cattle entry. The study site is located in the Ellett Valley of Montgomery County in Southwest Virginia, USA within the Valley and Ridge physiographic province. A physiographic province is a geographic region with distinctive geomorphology. The property encompasses approximately 660 acres and is divided into the 396-acre North (upstream) parcel and 264-acre South (downstream) parcel (Figure 1). Elevation varies from approximately $450 \mathrm{~m}$ at the river to $845 \mathrm{~m}$ at the highest points on the ridgetop.

The North Fork of the Roanoke River runs through both par-

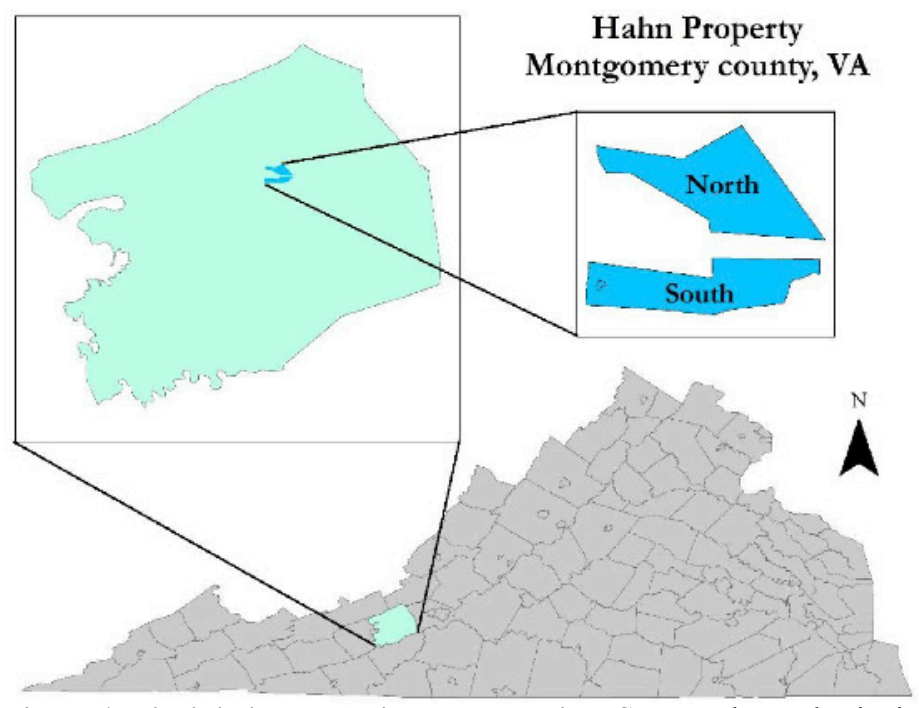

Figure 1. Virginia is located in eastern United States. The study site is specifically located in the Ellett Valley of Montgomery County, Virginia, USA. The study site is divided into the North and South parcel by the property of an outside landowner. Parcel, in the context of this research project, is defined as a plot of land.

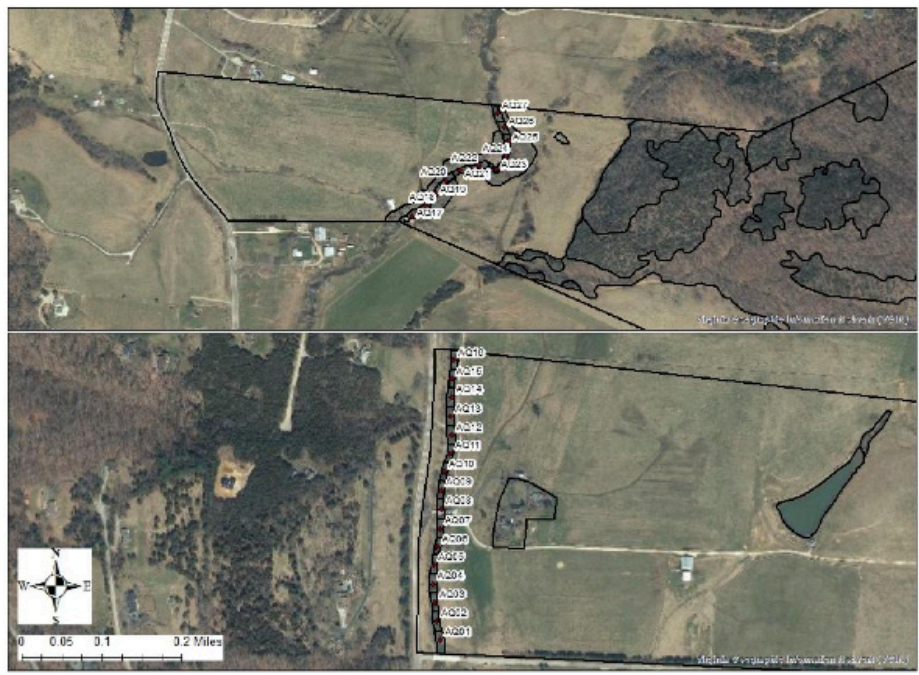

Figure 2. Sample reach distribution in the North (top map layer) and South (bottom map layer) parcels of the North Fork Roanoke River flowing through the study site. The North parcel is upstream of the South parcel. The North parcel river channel is far more sinuous than the South parcel. Sample reaches were $30 \mathrm{~m}$ long with 16 reaches in the South and 11 reaches in the North parcel due to the differing lengths of the parcels.

cels with an upstream length of $335 \mathrm{~m}$ and a downstream length of $488 \mathrm{~m}$. The two parcels are separated by approximately $1.17 \mathrm{~km}$ of stream running through privately owned agricultural land that is typical of the North Fork watershed. Cattle grazing occurs by the river in select areas, throughout the pastures, and into the highlands on each parcel. Cattle are allowed year-round access to the river on the North parcel but are excluded from accessing the river due to bank fencing and steeper banks on the South parcel (Figure 2). The land use of the riparian zone in the South parcel is primarily pas- 
ture with scattered trees. The relative riparian zone width measures less than $5 \mathrm{~m}$ because the stream is bordered by pasture on one side and a road on the other. The South parcel also appears to have been channelized in the past due to its straightened morphology and deteriorating concrete bank structures. Conversely, the North parcel of the river has a wider, more densely forested riparian zone, easy and consistent livestock access, and a low water crossing located at its downstream end, which alters flow for the entire upstream section (Figure 2). The North and South parcels have similar cover types with deciduous forest ( $>50$ years) covering most of the forested portion of the property. American sycamore (Platanus occidentalis) and maple (Acer spp) species dominate the riparian areas surrounding the North Fork of the Roanoke River.

Sampling Design

The North Fork of the Roanoke River flows through two geographically separate parcels within the study area, North (upstream) and South, (downstream) - with section lengths of $335 \mathrm{~m}$ and $488 \mathrm{~m}$ respectively (Figure 1). These two parcels are separated by 1.17 $\mathrm{km}$ of river and have substantially different riparian habitat and land use impacts.

By comparing the North and South parcel, the habitat quality and ecological health can be quantitatively compared to determine how they differ between parcels in response to differing environmental stressors and therefore assess the implications for conservation management. In order to compare the aquatic health of the two parcels with contrasting physical features each parcel was divided into $30 \mathrm{~m}$ reaches for the collection of field data, with 16 sample reaches in the South parcel and 11 in the North parcel for a total of twenty-seven $30 \mathrm{~m}$ sample reaches.

\section{Field Survey}

\section{Physical Habitat Characterization}

The physical characteristics of each sample reach were assessed following the criteria of the Ohio EPA Qualitative Habitat Evaluation Index and Use Assessment (QHEI) under the metrics of substrate, instream cover, channel morphology, bank erosion and riparian zone, pool/glide, riffle/run, and gradient (Ohio EPA, 2006). A handheld GPS unit was used to navigate to a point at the center of each of the 27 sample reaches. These central points were determined beforehand using arcmap. Reaches from downstream to upstream were evaluated to reduce sediment disturbance. Once each category was scored, they were summed to obtain an overall habitat score for each sample reach. Category scores were whole numbers; however, categories that recorded scores for left and right banks separately would be averaged together for an overall category score that was rounded to one decimal place.

\section{Macroinvertebrate Collection}

Following EPA RBP macroinvertebrate collection techniques, 6 macroinvertebrate kick net samples were collected using a $1 \mathrm{~m}$ D-frame net per sample reach (Barbour et al., 1999). Starting at a point approximately $5 \mathrm{~m}$ downstream from the center, a kick net $1 \mathrm{~m}$ from each bank and one kick net from the center was collected. This was then repeated at a point $5 \mathrm{~m}$ upstream of the center point for a total of six kicks per sample reach. Macroinvertebrates were searched for on rocks or woody debris surrounding the kick net site by lifting up rocks and debris for approximately five minutes per kick net. After picking through the debris in each kick netting, the macroinvertebrate sample was emptied into an $8 \mathrm{oz}$ glass jar of $95 \%$ ethanol, specifically labeled for the sample reach and returned to the lab for identification.

\section{Data Analysis}

\section{Physical Habitat}

The sum of the habitat metric scores in the QHEI for each sample reach were ranked on a scale of $0-100$ with 0 being poor habitat and 100 being optimal habitat. Individual scores were then ranked as detailed by the Ohio EPA: > 70 Excellent, 55-69 Good, 43-54 Fair, 30-42 Poor, < 30 Very Poor (Ohio EPA, 2006). Mean and standard deviation of the QHEI scores for each section were calculated.

\section{Macroinvertebrates}

The macroinvertebrate samples were collected and scored using VSCI to determine ecosystem stress levels. A total count of macroinvertebrates was conducted for each sample reach. VSCI calculates total taxa, Ephemeroptera, Plecoptera, and Trichoptera (EPT) taxa, percent Ephemeroptera, percent Plecoptera + Trichoptera less Hydropsychidae, percent Scrapers, percent Chironomidae, percent Top 2 Dominant, and HBI (family) using techniques as referenced (VDEQ, 2008). Samples were combined from all four reaches to reflect the RBP "Field sampling procedures for a single habitat," which suggest the sampling of a $100 \mathrm{~m}$ reach that represents the characteristics of the stream being sampled. Taxa richness was determined by calculating the number of species in EPT orders in each $120 \mathrm{~m}$ sample. The EPT measure is sensitive to water quality making it a good indicator of stream condition (Lenat and Barbour, 1994). The numeric score of each sample reach grouping was used to categorize the stress of the aquatic life based upon the following scale as detailed by the Virginia Department of Environmental Quality ( > 73 Excellent, 60-72 Good, 43-59 Stress, < 42 Severe Stress) (VDEQ, 2008). The mean and standard deviation of the VSCI scores was calculated for the upstream and downstream sections. Pollution tolerant macroinvertebrates were worth fewer points in the VSCI scoring system and so reaches under more stress with more generalist, pollution tolerant macroinvertebrates received lower scores than those areas with pollution sensitive macroinvertebrates that indicated high water quality (Table 1).

\section{RESULTS}

The longer downstream parcel had a lower mean QHEI (i.e. habitat) score of $49.7 \pm 3.7$ compared to the upstream section, with a mean score of $57.2 \pm 6.5$ (Figure 3). The downstream parcel had an average VSCI score of $74.9 \pm 5.4$, which was higher than the upstream parcel with a score of $60.8 \pm 20.9$ (Figure 4). Table 2 displays a summary of the QHEI and VSCI scores by sample reach grouping. Table 1 displays the macroinvertebrates that were collected in each parcel. 


\begin{tabular}{|c|c|c|}
\hline Family & South parcel number & North parcel number \\
\hline Baetidae + & 66 & 8 \\
\hline Caenidae + & 21 & 9 \\
\hline Ephemerellidae + & 18 & 0 \\
\hline Ephemeridae + & 5 & 3 \\
\hline Heptageniidae + & 245 & 132 \\
\hline Hydroptilidae + & 30 & 2 \\
\hline Leptophlebiidae + & 32 & 24 \\
\hline Oligoneuriidae + & 45 & 33 \\
\hline Perlidae + & 11 & 7 \\
\hline Perlodidae + & 6 & 0 \\
\hline Psephenidae + & 131 & 90 \\
\hline Aeshnidae & 1 & 0 \\
\hline Coenagrionidae & 2 & 0 \\
\hline Corydalidae & 68 & 28 \\
\hline Dystiscidae & 16 & 2 \\
\hline Elmidae & 327 & 143 \\
\hline Gomphidae & 13 & 4 \\
\hline Gyrinidae & 1 & 0 \\
\hline Hydrachnidae & 1 & 0 \\
\hline Hydropsychidae & 134 & 69 \\
\hline Athericidae - & 55 & 51 \\
\hline Ceratopogonidae - & 11 & 0 \\
\hline Chironomidae - & 129 & 168 \\
\hline Ephydridae - & 2 & 0 \\
\hline Sialidae - & 6 & 3 \\
\hline Tipulidae - & 13 & 3 \\
\hline Total & 1389 & 779 \\
\hline
\end{tabular}

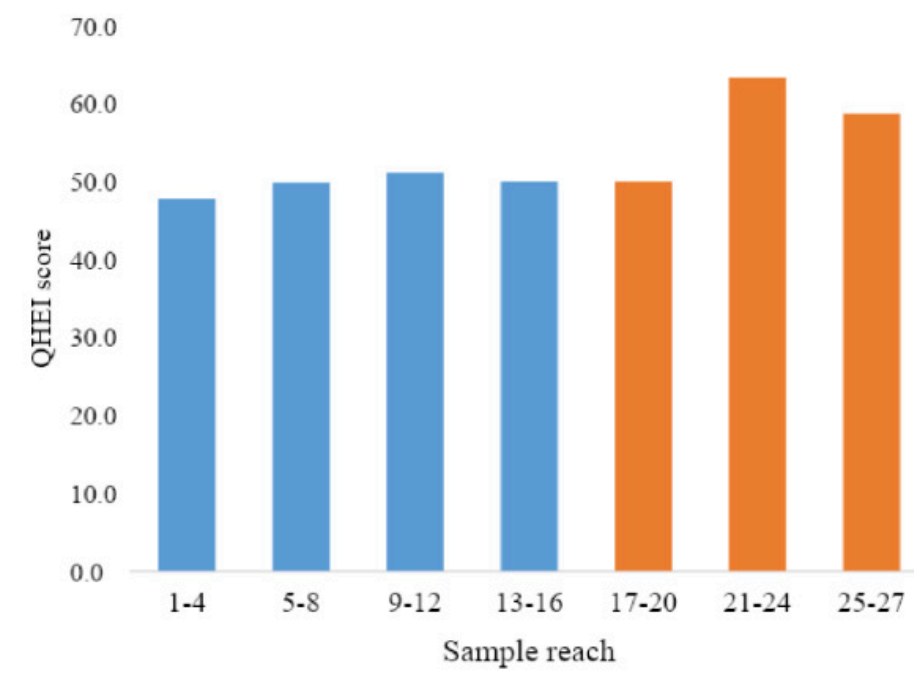

Figure 3. Habitat scores derived from a QHEI assessment of the South parcel (downstream) and North parcel (upstream) of the North Fork Roanoke River. The South parcel spans sample reaches 1-16 while the North parcel spans sample reaches 17-27. The metrics that were evaluated for QHEI are those viewed as most impactful and significant to aquatic vertebrates and invertebrates. A higher habitat score indicates a higher quality habitat.

\begin{tabular}{|c|c|c|c|c|c|}
\hline Section & $\begin{array}{l}\text { Sample } \\
\text { Reach }\end{array}$ & $\begin{array}{l}\text { Average } \\
\text { QHEI } \\
\text { Score }\end{array}$ & $\begin{array}{l}\text { QHEI } \\
\text { Assessment }\end{array}$ & $\begin{array}{l}\text { Average } \\
\text { VSCI } \\
\text { Score }\end{array}$ & $\begin{array}{l}\text { VSCI } \\
\text { Assessment }\end{array}$ \\
\hline South & $1-4$ & 47.8 & Fair & 80.4 & Excellent \\
\hline South & $5-8$ & 49.9 & Fair & 78.4 & Excellent \\
\hline South & $9-12$ & 51.1 & Fair & 72.1 & Good \\
\hline South & $13-16$ & 50.0 & Fair & 68.6 & Good \\
\hline North & $17-20$ & 50.0 & Fair & 39.6 & $\begin{array}{l}\text { Severe } \\
\text { Stress }\end{array}$ \\
\hline North & $21-24$ & 63.4 & Good & 73.5 & Excellent \\
\hline North & $25-27$ & 58.7 & Good & 69.4 & Good \\
\hline
\end{tabular}

Table 2. Average QHEI and VSCI scores for sample reaches in the South (downstream) and North (upstream) parcels of

Table 1. VSCI results showing macroinvertebrate families that are pollution sensitive (high water quality) and those that are pollution tolerant (low water quality) collected in the downstream and upstream sections of the North Fork Roanoke River. "+" indicates that the macroinvertebrate species was pollution sensitive. "-" indicates that the macroinvertebrate species was pollution tolerant. the North Fork Roanoke River. The QHEI and VSCI scores are compared to their respective indexes to give a category of habitat quality and ecological stress being experienced by macroinvertebrate organisms of the sample reaches. Reaches 17-20 experienced severe ecological stress demonstrated by VSCI scores, whereas the other reaches were good to excellent. All reaches experienced fair to good habitat quality as indicated by the QHEI. 


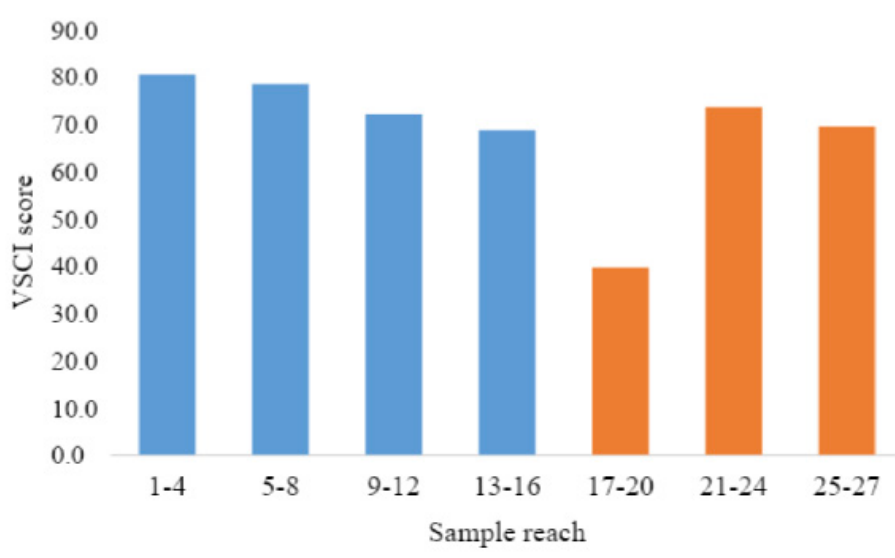

Figure 4. VSCI scores indicative of the level of environmental stress experienced by aquatic organisms. Higher scores indicate less stress and lower scores indicate higher stress. The South parcel (downstream) scored higher than the North parcel (upstream). The South parcel spans sample reaches 1-16 while the North parcel spans sample reaches 17-27.

\section{DISCUSSION}

It was hypothesized that stream reaches subjected to consistent livestock use and reduced flow rates related to a low-water vehicle crossing would exhibit increased bank erosion and siltation resulting in lower habitat quality and increasingly stressed aquatic communities. The results support the original hypothesis. Factors affecting habitat and ecological health of the North Fork Roanoke River within the study reaches include location within a watershed with widespread agriculture, past channelization of the downstream section, lack of riparian vegetation in the downstream section, livestock access to the river especially in the upstream section, and the low-water vehicle crossing in reach 17 of the upstream section. The river's location in a watershed with widespread agriculture makes it more likely to experience degraded ecosystem quality due to runoff, increased nutrients, and alteration of channel morphology (Omernik, 1976; Corvallis, 1977; Petersen, 1992). The entire downstream section has been channelized in the past, as evidenced by a lack of sinuosity and a concrete wall lining the stream, which contributed to the section's overall lower habitat score compared to the upstream parcel, due to a lower channel morphology subscore (Figure 2). The downstream section has a very narrow riparian zone bordered by pasture on one side and a roadway on the other. Roads near waterways produce non-point source pollution from sediment, nutrients, and contaminants (Gjessing et al., 1984). However, the higher VSCI scores (Figure 4) indicate a healthier aquatic ecosystem in the downstream section despite lower habitat scores. Fencing that restricts livestock access in this area likely contributed to the higher VSCI scores in the downstream section. Another factor that could explain the more diverse aquatic ecosystem in the downstream section, despite lower quality habitat, is the $1.17 \mathrm{~km}$ river stretch between the upstream and downstream reaches. Through this stretch of river, the riparian zone is forested and there is no apparent livestock entry. Thus, instream and near stream biological processes, such as nutrient uptake, processing by periphyton (i.e. denitrification) and organic matter retention may reduce nutrient loading downstream (Roberts and Mulholland, 2007). Furthermore, Roley et al. (2012) demonstrated that restored floodplains at the reach scale can reduce stream nitrate concentration through denitrification in an agricultural watershed.

In the upstream section, livestock have easier access to the river with no exclusion fencing. The fair to good habitat scores of the upstream section resulted from the adequate riparian vegetation on both banks of the river as well as no channelization as evidenced by sinuosity and absence of channelization structures. The only area in the upstream parcel that received a habitat score of "fair" were reaches 17-20 (Table 2). These reaches are directly upstream of the low-water vehicle crossing resulting in increased sedimentation and pooling. These reaches also experience the majority of cattle entry, which was directly observed along with numerous heavily used, eroding trails leading into the water and feces in the river. All of which directly and indirectly contributed to erosion, sedimentation, and lower habitat scores. Reaches 17-20 also received the lowest VSCI score of, "severely stressed" (Table 2). Thus, the aquatic community in these reaches is stressed possibly due to the increased siltation and obstruction of dispersal due to the clogged culverts and livestock use, resulting in fewer pollution sensitive macroinvertebrates (Clarkin et al., 2006). Ranganath et al. (2009) conducted a study in the North Fork of the Roanoke River to analyze livestock exclusion impact on riparian vegetation, channel morphology, and benthic communities. Reaches with livestock exclusion were found to support improved geomorphic and riparian vegetation conditions but did not show significant differences in benthic macroinvertebrate assemblages from the experimental reaches without livestock exclusion (Ranganath et al., 2009). These findings suggest that local reach-scale livestock exclusion positively affects some habitat characteristics related to bank structure and channel morphology; however, larger-scale, watershed features such as upstream riparian forest patches are necessary to affect change in aquatic assemblages. The findings of Ranganath et al. (2009) support the findings in the South parcel. Although the South parcel habitat quality is reduced due to channelization and narrow riparian zone, high quality macroinvertebrate assemblages persist possibly due to the upstream forested riparian corridor of the $1.17 \mathrm{~km}$ separating the North and South parcel.

Macroinvertebrates are valuable indicators of the stress level that the greater aquatic communities are experiencing. Siltation is especially problematic to pollution sensitive macroinvertebrates, which are primarily clingers and crawlers, because the interstitial spaces, which are the minute spaces between grains of sand or other substrate, under rocks disappear as the rocks become embedded in the sediment. Silt deposited in layers causes the tops of the rocks to become less stable and makes the adaptations that surveyed macroinvertebrate species have such as claws, suction, or silk less effective (Braccia and Voshell, 2007). Sensitive taxa such as Ephemeroptera, Plecoptera, and Trichoptera decrease in abun- 
dance in response to sub-optimal habitat conditions. In response to the absence of pollution sensitive taxa, pollution tolerant taxa like Chironomidae and burrowers increase in abundance as they are capable of utilizing fine sediment (Braccia \& Voshell, 2007).

Because the Roanoke Logperch, a federally endangered species, has been confirmed to inhabit the North Fork, maintaining good water quality and habitat is a priority (Rosenberger, 2007). The adverse effects of local development and disturbances, as well as the positive effects of local upstream optimal habitat characteristics, on both ecological health and habitat quality as suggested by this research as well as others demonstrate the need for habitat management techniques that will improve the health of aquatic ecosystems and the likelihood of imperiled species persistence (Sponseller et al., 2001; Roberts and Mulholland, 2007; Roley et al., 2012). Private landowners could contribute to improving habitat quality through the exclusion of livestock from the waterway and adjoining riparian zone. Cattle exclusion would result in improved riparian vegetation growth, reduced bank erosion, and improved substrate composition allowing for overall decreased siltation and improved water quality (Sarr, 2002; Agourdis et al., 2005). Prevention of cattle entry through the use of riverbank fencing is an effective option that results in a rapid recovery of riparian vegetation, reduced water quality degradation at downstream sites, decreased average stream width, decreased sediment deposition on gravel bottoms, pool establishment, and improved water temperatures (Van Velson, 1979; Fitch and Adams, 1998; Miller et al., 2010). With the baseline information gained through this research, management techniques such as those previously detailed can be applied and evaluated for efficacy in the context of privately owned agricultural lands. Systematic application of research techniques such as VSCI and QHEI may allow for the monitoring and effective management of riverine resources within privately owned agricultural watersheds. These results suggest that restoration efforts that exclude livestock through riverbank fencing and remove the low water crossing from the North parcel will increase the MIV assemblages in those few affected sample reaches to the level of good-excellent macroinvertebrate health that surrounds the area due to the surrounding suitable habitat indicated by QHEI scores.

The overall habitat quality on the property ranges from fair to good on the QHEI scale and the overall macroinvertebrate health is good to excellent on the VSCI scale with the exception of the beginning of the upstream section which has severely stressed aquatic communities likely from the presence of a low water vehicle crossing and convenient cattle entry.

Urban and suburban development of privately held forest and farmland, which are critical reservoirs of biodiversity, results in simplified native biodiversity and ecological relationships (Knight, 1999). Quantitative studies assessing activities such as agriculture (e.g. cattle grazing) in the context of private land are lacking. Understanding the specific factors that degrade ecosystems of privately owned agricultural ecosystems will help optimize land management for conservation of biodiversity. Privately owned lands span the United States and support the abundance of threatened and endangered species, lending a major opportunity to play significant role in biodiversity conservation. Future research throughout the United States in areas of high private property concentration will help to increase understanding of factors adversely affecting the ecosystem of private lands, improve management efficacy, and allow private lands to fulfill their potential in contributing to and advancing biodiversity conservation.

\section{REFERENCES}

Agourdis, C., Edwards, D., Workman, S., Bicudo, J., Koostra, B., Vanzant, E., and Taraba, J. (2005). Streambank erosion associated with grazing practices in the humid region. Transaction of the ASAE, 48(1), 181-190.

Barbour, M. T., J. Gerritsen, B. D. Snyder, and J. B. Stribling (1999). Rapid Bioassessment Protocols for Use in Streams and Wadeable Rivers: Periphyton, Benthic Macroinvertebrates and Fish, Second Edition. EPA 841-B-99-002. U.S. Environmental Protection Agency; Office of Water; Washington, D.C.

Belsky, A., Matzke, A., and Uselman, S. (1999). Survey of livestock influences on stream and riparian ecosystems in the western United States. Journal of Soil and Water Conservation, 54(1), 419-431.

Blann, K., Anderson, J., Sands, G., and Vondracek, B. (2009). Effects of agricultural drainage on aquatic ecosystems: a review. Critical reviews in environmental science and technology, 39(11), 909-1001.

Braccia, A., and Voshell, J. (2007). Benthic macroinvertebrate responses to increasing levels of cattle grazing in Blue Ridge Mountain streams, Virginia, USA Environmental Monitoring and Assessment, 131(1-3), 185-200.

Corvallis Environmental Research Laboratory. (1977). Nonpoint source-stream nutrient level relationships: a nationwide study (Vol. 77). EPA.

Clarkin, K., Keller, G., Warhol, T. and Hixson, S. (2006). Low-water crossings: geomorphic, biological, and engineering design considerations.

Environmental Protection Agency (2015). Watershed Report, available: https://watersgeo.epa.gov/watershedreport/?comid=8628425s [3 October 2018].

Fitch, L., and Adams, B. (1998). Can Cows and Fish Co-Exist? Canadian Journal of Plant Science, 78(2), 191-198.

Gjessing, E., Lygren, E., Berglind, L., Gulbrandsen, T., and Skanne, R. (1984). Effect of highway runoff on lake water quality. Science of the Total Environment, 33(1-4), 245-257.

Herbst, D. B., Bogan, M. T., Roll, S. K., and Safford, H. D. (2012). Effects of livestock exclusion on in-stream habitat and benthic invertebrate assemblages in montane streams. Freshwater Biology, 57(1), 204-217.

Jenkins, C. N., Van Houtan, K. S., Pimm, S. L., and Sexton, J. O. (2015). U.S. protected lands mismatch biodiversity priorities. Proceedings of the National Academy of Sciences, 112(16), 5081-5086.

Kauffman, J., and Krueger W. (1984). Livestock impacts on riparian ecosystems and streamside management implications... a review. Journal of Range Management, 37(5), 430-438.

Knight, R. L. (1999). Private Lands: the neglected geography. Conservation Biology, 13(2), 223-224.

Llansó, R. J., and Dauer, D. M. (2002). Methods for calculating the Chesapeake Bay benthic index of biotic integrity. Prepared for the Chesapeake Bay Benthic Monitoring Program. Accessed November, 22, 2010.

Lenat, D., and Barbour, M. (1994) Using benthic macroinvertebrate community structure for rapid, cost-effective, water quality monitoring: rapid bioassessment: Biological monitoring of aquatic systems, Boca Raton, Florida: Lewis Publishers, 187-215.

Lynsen, J. (2016) 56 Million Acres Voluntarily Conserved in America, National Land Trust Census Reveals, available: http://www.landtrustalliance.org/ node/1693 [21 August 2018].

Miller, J., Chanasyk, D., Curtis, T., Entz, T., and Willms, W. (2010). Influence of streambank fencing with a cattle crossing on riparian health and water quality of the Lower Little Bow River in Southern Alberta, Canada, Agricultural Water Management, 97(2), 247-258.

Ohio, E. P. A. (2006). Methods for assessing habitat in flowing waters: using the Qualitative Habitat Evaluation Index (QHEI). Ohio Environmental Protection Agency. 
Omernik, J. M. (1976). The influence of land use on stream nutrient levels (Vol. 76, No. 14). U.S. Environmental Protection Agency, Office of Research and Development, Corvallis Environmental Research Laboratory, Eutrophication Survey Branch.

Parker, D. P. (2004). Land trusts and the choice to conserve land with full ownership or conservation easements. Natural Resources Journal, 483-518.

Petersen Jr, R. C. (1992). The RCE: a riparian, channel, and environmental inventory for small streams in the agricultural landscape. Freshwater Biology, 27(2): 295-306.

Platt, R. H. (2004). Land use and society, revised edition: Geography, law, and public policy. Island Press.

Ranganath, S. C., Hession, W. C., and Wynn, T. M. (2009). Livestock exclusion influences on riparian vegetation, channel morphology, and benthic macroinvertebrate assemblages. Journal of Soil and Water Conservation, 64(1), $33-42$.

Rankin, E. T. (1989). The Qualitative Habitat Evaluation Indes [QHEI]: Rationale, Methods, and Application.

Raven, P. J., Holmes, N. T., Dawson, F. H., Fox, P. J., Everard, M., Fozzard, I. R., and Rouen, K. J. (1998). River habitat quality. Environment Agency: Bristol.

Roberts, B. J., and Mulholland, P. J. (2007). In-stream biotic control on nutrient biogeochemistry in a forested stream, West Fork of Walker Branch. Journal of Geophysical Research: Biogeosciences, 112(G4).

Roley, S. S., Tank, J. L., Stephen, M. L., Johnson, L. T., Beaulieu, J. J., and Witter, J. D. (2012). Floodplain restoration enhances denitrification and reach-scale nitrogen removal in an agricultural stream. Ecological Applications, 22(1), 281-297.

Rosenberger, A. E. (2007) An update to the Roanoke logperch recovery plan. Final Report to the US Fish and Wildlife Service, Gloucester, VA, 51.

Sarr, D. A. (2002). Riparian livestock exclosure research in the western United States: a critique and some recommendations. Environmental Management, 30(4), 516-526.

Southern Appalachian Vitality Index. (2016a) Landscape Management and Ownership, available: http://southernappalachianvitalityindex.org/land/land-management-and-ownership [18 February 2019].

Southern Appalachian Vitality Index. (2016b) Riparian Buffers, available: http:// southernappalachianvitalityindex.org/landscape-condition/riparian-buffers [18 February 2019].

Sponseller, R. A., Benfield, E. F., and Valett, H. M. (2001). Relationships between land use, spatial scale and stream macroinvertebrate communities. Freshwater biology, 46(10), 1409-1424.

Stein, B. A., Kutner, L. S., and Adams, J. S. (2000) Precious heritage: the status of biodiversity in the United States, Oxford University Press on Demand.

Sutherland, A., Meyer, J., and Gardiner, E. (2002). Effects of land cover on sediment regime and fish assemblage structure in four southern Appalachian streams. Freshwater Biology, 47(9), 1791-1805.

Trimble, S. W., and Mendel, A. C. (1995). The cow as a geomorphic agent - a critical review. In Biogeomorphology, Terrestrial and Freshwater Systems (pp. 233-253).

Van Velson, R. (1979). Effects of livestock grazing upon rainbow trout in Otter Creek. In Forum-grazing and riparian/stream ecosystems. OB Cope, ed. Trout Unlimited, Denver, $C O$ (pp. 53-55).

Virginia Department of Environmental Quality. (2008) Biological Monitoring Program Quality Assurance Project Plan for Wadeable Streams and Rivers, available: https://www.deq.virginia.gov/Portals/0/DEQ/Water/WaterQualityMonitoring/BiologicalMonitoring/BioMonQAPP_13Aug2008.pdf [19 February 2019].

Wang, L., Lyons, J., Kanehl, P., and Gatti, R. (1997). Influences of watershed land use on habitat quality and biotic integrity in Wisconsin streams. Fisheries, $22(6), 6-12$.

Waters, T. F. (1995). Sediment in Streams: Sources, Biological Effects, and Control. American Fisheries Society.

Yoder, C. O. (1991). The integrated biosurvey as a tool for evaluation of quatic life use attainment and impairment in Ohio surface waters. Biological criteria: Research and regulation, 110-122. 